\title{
Price Destabilizing Speculation
}

\section{Citation}

Hart, Oliver D., and David M. Kreps. 1986. Price destabilizing speculation. Journal of Political Economy 94(5): 927-952.

\section{Published Version}

doi:10.1086/261418

\section{Permanent link}

http://nrs.harvard.edu/urn-3:HUL.InstRepos:3448679

\section{Terms of Use}

This article was downloaded from Harvard University's DASH repository, and is made available under the terms and conditions applicable to Other Posted Material, as set forth at http:// nrs.harvard.edu/urn-3:HUL.InstRepos:dash.current.terms-of-use\#LAA

\section{Share Your Story}

The Harvard community has made this article openly available.

Please share how this access benefits you. Submit a story.

Accessibility 


\title{
Price Destabilizing Speculation
}

\author{
Oliver D. Hart
}

Massachusetts Institute of Technology

\section{David M. Kreps}

Stanford University

\begin{abstract}
It is sometimes asserted that rational speculative activity must result in more stable prices because speculators buy when prices are low and sell when they are high. This is incorrect. Speculators buy when the chances of price appreciation are high, selling when the chances are low. Speculative activity in an economy in which all agents are rational, have identical priors, and have access to identical information may destabilize prices, under any reasonable definition of destabilization. It takes extremely strong conditions to ensure that speculative activity (of the commodity storage variety) "stabilizes" prices, even in a very weak sense.
\end{abstract}

\section{Introduction}

Do speculators stabilize prices? This old question has been the subject of a large literature, going back as far as Smith (1789/1937) and including Mill (1921), Friedman (1953), Baumol (1957), Telser (1959), Farrell (1966), and Samuelson (1971), among others. (For a comprehensive bibliography, see Goss and Yamey [1978].) The case that speculators must stabilize prices is succinctly put in the adage that

Financial assistance from the Social Science Research Council of the United Kingdom, the International Center for Economics and Related Disciplines at the London School of Economics, the National Science Foundation (grants SES-8006407 and SES8408586), the Office of Naval Research (contract N00014-77-C-0518), Harvard University, and the Sloan Foundation is gratefully acknowledged. We would like to thank the editor and two referees for helpful suggestions and comments. 
(rational) speculators "buy cheap and sell dear," thereby raising low prices and lowering high prices. To quote from Friedman (1953, p. 175), "People who argue that speculation is generally destabilizing seldom realize that this is largely equivalent to saying that speculators lose money, since speculation can be destabilizing in general only if speculators on the average sell when the currency is low in price and buy when it is high." Thus it seems that only irrational speculators could destabilize prices.

In fact, matters are more complicated than this, as a number of authors have noted. This is because there is less to the "buy cheap and sell dear" adage than meets the eye. Speculators will buy when the chances of price appreciation are high, which may or may not be when prices are low (see Kohn 1978). This observation in fact underlies a number of examples of profitable, destabilizing speculation that were developed in the 1950s and 1960s (see Baumol 1957; Telser 1959; Farrell 1966). These examples are not conclusive, however, since they rely either on there being a small number of imperfectly competitive speculators or on nonspeculators having irrational expectations. The purpose of the present paper is to show that speculation can be destabilizing even when speculators are competitive and both speculators and nonspeculators have rational expectations.

Any theory of speculative behavior must address the thorny question of how to define speculation. Despite the many attempts to do this in the literature, a satisfactory general definition is still not available (and probably never will be; see, e.g., Johnson [1976]). We shall not attempt to give one here. Rather we will study a very specific situation in which there is a fairly natural and (we hope) noncontroversial notion of speculation and speculators. We will also make no attempt to give a general definition of price destabilization. The cases we will study are sufficiently specific that the terms stabilization and destabilization have simple and intuitive meanings.

Our basic model concerns the market for a commodity such as wheat (although we will show that the model can also be interpreted as one for a durable asset). The market meets at a sequence of discrete dates. There are two types of agents. One type, nonspeculators or consumers, trades in the market only for purposes of immediate consumption. The second type, speculators, buys with the intention of holding the commodity and then selling at a higher price at a later date. (Thus in our model "speculation" is synonymous with "storage.") Exogenous uncertainty in the model comes from the fact that the nonspeculative demand schedule at each date is random, drawn according to some probability distribution. (This distribution may depend on the position of demand in the previous period.) Speculators are assumed to know this probability distribution and to have rational expectations 
about the resulting stochastic evolution of prices. Speculators are assumed to know the current position of the demand for consumption schedule, and they may possibly possess some further information concerning future levels of this schedule. The inferences they draw from this information are always correct in the Bayesian sense, and they all have access to the same information. Consumers also know these things, but that they do so is unimportant: They enter the market only once, buying only for immediate consumption. (Models along these lines may be found in a number of papers; see, e.g., Kohn [1978] and Scheinkman and Shechtman [1983].)

Our objective is to show that such storage/speculation can lead to less stable equilibrium prices. The basic example of this runs roughly as follows. Suppose that the sequence of consumption demand schedules is independent and identically distributed but that at any date there may be portents about next period's schedule. Specifically, assume that demand in each period is either very high or very low, that the chance of high demand is quite small, and that whenever next period's demand will be high, there is in this period a signal that this will happen. Suppose, however, that this signal is imperfect in the sense that, while it always appears prior to high-demand periods, it also sometimes appears prior to low-demand periods. It does the latter sufficiently infrequently that the chance of high demand next period conditional on having observed the sign is greater than the (marginal) probability of high demand but also sufficiently frequently that it is wrong more times than not. (Numbers will be given in the body of the paper.) Now suppose that in the current period consumption demand is low and the signal is present. Speculators may then buy up some of the supplies of the commodity, anticipating the chance of a high price next period. If the signal turns out to be accurate so that the high price does occur, then this is price stabilizing in the sense that prices are higher this period and lower next. But suppose the signal this period is inaccurate and moreover that there is no signal next period. Then next period speculators will dump their stored supplies onto the consumption market without providing any further demand. (The fact that the signal is absent means that high prices cannot occur in the next period, and so in this period there is no speculative motive.) This might well depress prices next period to a level lower than they would ever get without the presence of speculators. Now it is by no means clear that this leads to less stable prices in any precise sense, but (by playing with elasticities of demand for consumption) we will be able to flesh out this example and to show that destabilization may indeed occur.

The existence of a noisy signal is not crucial to the construction of lessened stability from speculation. Destabilizing speculation can oc- 
cur even if speculators have perfect foresight about the future as long as this foresight is limited, in particular, if speculators at date $t$ know (perfectly) the position of consumption demand at dates $t, t+1, \ldots, t$ $+k$, but nothing more. But while one can always construct an example in which speculation is destabilizing for such an information structure for any finite $k>0$, in the extreme cases $k=0$ and $k=\infty$, speculation will always be stabilizing (in a very weak sense). And for a given economy (with everything held fixed except the size of $k$ ) this will be true for large values of $k$.

The thrust of this paper is that speculative activity can destabilize prices (in reasonable circumstances) - not that it will. It should also be noted that whether or not speculation stabilizes prices is in some sense the wrong question. One really ought to be interested in the welfare implications of speculation. One may feel intuitively that price stabilization is "good," but, if so, one's intuition is faulty (see Newbery and Stiglitz 1984). We study the impact of speculation on price stability rather than on welfare because in our model the welfare effects of speculation turn out to be complicated. The reader should, however, bear in mind throughout that welfare and price stabilization can sometimes be related in a surprising fashion. We will indicate this in the context of our basic example and then comment on it generally in the final section.

The paper is organized as follows. In Section II, we give our "canonical" example of price destabilizing speculation. In Sections III and IV, we present a more general model and analyze the characteristics of equilibrium. (Technical details are left for the App.) Section V presents the limited results that we have obtained concerning when speculation might be said to be price stabilizing. We sum up in Section VI.

\section{An Example of Destabilizing Speculation}

We first present a very simple example to show how speculation can be destabilizing (under any reasonable definition of stability). We begin by giving a brief description of the economy we shall be considering. Imagine a market for a storable commodity. This market meets at a sequence of dates $t=\ldots,-1,0,1,2, \ldots$ Supply to this market is inelastic; we will explain the sources of this supply shortly. There are two types of demand: demand for consumption purposes and demand for storage or speculative purposes.

Consumption demand derives from consumers who are in the market just once. That is, a new generation of consumers enters at each date $t$ and then exits forever. We suppose that consumption demand in period $t$ depends on the equilibrium price of the commodity, $p_{t}$, 
and on a random taste parameter, $\theta_{t}$. That is, the consumption demand schedule shifts in or out from period to period, with $\theta_{t}$ a description of the position of the schedule at date $t$. We write $D\left(p_{t} ; \theta_{t}\right)$ for this demand schedule.

The second source of demand is speculative or storage demand (we use the two terms interchangeably). We suppose that there are overlapping generations of competitive speculators, each speculator living for just two periods. Speculators, who consume only the numeraire commodity, enter the market when young with a fixed endowment of the numeraire good, some of which they spend on the storable commodity. They then store this commodity for one period, possibly subject to some wastage, and supply inelastically what comes out of storage to the market when they are old. There is also a constant exogenous inelastic supply (fresh crop) each period, which we denote by $X$. Speculators' storage decisions depend on the current price, $p_{t}$, and on their expectations about next period's price. These expectations will be rational.

All speculators (at date $t$ ) observe the current consumption demand parameter, $\theta_{t}$. There may also be additional public information $\xi_{t}$ concerning future demand. For example, $\xi_{t}$ might be $\theta_{t+1}$ : the consumption demand parameter is known one period in advance. More generally, $\xi_{t}$ might represent noisy information about $\theta_{t+1}, \theta_{t+2}, \ldots$

We can now describe our example of destabilizing speculation. Imagine that in each period $\theta_{t}$ is either $\bar{\theta}$ or $\theta$. The sequence $\left\{\theta_{t}\right\}$ is an independently and identically distributed (i.i.d.) sequence, with the probability that $\theta_{t}=\bar{\theta}$ equal to .01 . Consumption demand when $\theta_{t}=$ $\bar{\theta}$ is perfectly elastic at a price of $\$ 1,000$. When $\theta_{t}=\underline{\theta}$, consumption demand is a bit more complex: From zero to 100 units, it is perfectly elastic at price $\$ 10.00$. Then the demand curve slopes downward: It is at price $\$ 9.00$ at 130 units, and it decreases thereafter, asymptoting at price $\$ 8.00$.

In each period 100 fresh units of the commodity are provided (i.e., $\underline{X}=100$ ). Speculators can store up to 50 units, getting back three for every five stored. Speculators maximize the expected present worth of income, with a zero interest rate. Their endowment of the numeraire is assumed to be large: they can afford to purchase 50 units even if the price is $\$ 1,000$.

The key to this example is the information flow. At date $t$, besides $\theta_{t}$ there is available a signal $\xi_{t}$ that is an imperfect portent of the future. Specifically, $\xi_{t}$ is either $\underline{\xi}$ or $\bar{\xi}$. Whenever $\theta_{t+1}$ will equal $\bar{\theta}$, then $\xi_{t}=\bar{\xi}$; $\underline{\xi}$ indicates the impossibility of $\bar{\theta}$ next time. But $\xi_{t}=\bar{\xi}$ indicates only that $\bar{\theta}$ is possible. When $\theta_{t+1}=\theta$, then $\xi_{t}=\bar{\xi}$ with probability $1 / 11$ and $\xi_{t}=\underline{\xi}$ with probability $10 / 11$. Computation with Bayes's rule shows that when $\xi_{t}=\bar{\xi}$ the chance that $\theta_{t+1}$ will be $\bar{\theta}$ is .1. In terms of our 
TABLE 1

Transition Matrix for THE Markov Chain

\begin{tabular}{lllcc}
\hline & $\underline{\theta \xi}$ & $\underline{\theta \bar{\xi}}$ & $\bar{\theta} \underline{\underline{\xi}}$ & $\overline{\overline{\theta \xi}}$ \\
\hline$\overline{\theta \xi}$ & .9 & .1 & 0 & 0 \\
$\overline{\theta \bar{\xi}}$ & .81 & .09 & .09 & .01 \\
$\overline{\bar{\theta} \xi}$ & .9 & .1 & 0 & 0 \\
$\overline{\theta \xi}$ & .81 & .09 & .09 & .01 \\
\hline
\end{tabular}

Note.-Entries are $P\left(\phi_{t+1}=\right.$ column $\mid \phi_{t}=$ row $)$.

formulation, $\left\{\left(\theta_{t}, \xi_{t}\right)\right\}$ is a four-state Markov chain, with transition matrix given in table 1 .

The idea of this example is that, very occasionally, there is huge demand for the commodity $\left(\theta_{t}=\bar{\theta}\right)$. Such huge demand next period is foreshadowed this period by $\bar{\xi}$. But seeing $\bar{\xi}$ indicates only the possibility of huge demand next period-there remains substantial (.9) probability that demand will be small.

What will be equilibrium price behavior in this economy? First consider what would happen if there are no speculators in this economy at all. Then prices will be $\$ 1,000$ whenever $\theta_{t}=\bar{\theta}$ and $\$ 10.00$ whenever $\theta_{t}=\underline{\theta}$.

Now add the speculation/storage activity. Speculators will buy the commodity, up to their limit of 50 units, whenever $\theta_{t}=\underline{\theta}$ and $\xi_{t}=\bar{\xi}$. Doing so does not raise the current price above $\$ 10.00$, and there is some prospect (a .1 chance) that they will be able to sell next period at $\$ 1,000$, more than enough, given their storage technology and decision criterion, to justify the gamble. When $\theta_{t}=\bar{\theta}$, speculators will not buy: There are no prospects for price appreciation. And when $\theta_{t}=\underline{\theta}$ and $\xi_{t}=\xi$, speculators will not buy: The current price is no lowe $\bar{r}$ than $\$ 8.0 \overline{0}$, and next period's price can be no higher than $\$ 10.00$, which yields an insufficient return on the investment.

Price behavior with speculators, then, goes as follows. Whenever $\theta_{t}$ $=\bar{\theta}$, the equilibrium price is $\$ 1,000$, just as in the case with no speculators. And when $\theta_{t}=\underline{\theta}$, there are two possibilities: If $\xi_{t}=\bar{\xi}$, then speculators will take 50 units off the market. This will ensure that supply for consumption is not more than 80 units, and the equilibrium price will be $\$ 10.00$. If $\xi_{t}=\underline{\xi}$ and it was the case that $\xi_{t-1}=\underline{\xi}$, then supply for consumption is 100 (speculators bought neither last period nor this), and again equilibrium price is $\$ 10.00$. The one change from the economy without speculators (in terms of equilibrium prices) comes when $\theta_{t}=\underline{\theta^{*}}, \xi_{t}=\underline{\xi}, \theta_{t-1}$ was $\underline{\theta}$, and $\xi_{t-1}$ was $\bar{\xi}$. In this case, speculators do not buy this period, but they did buy last period. Supply for consumption is 130 units, and the equilibrium price is $\$ 9.00$. 
In other words, without speculation, price is sometimes $\$ 1,000$ and sometimes $\$ 10.00$ (much more often the latter). With speculation, price is $\$ 1,000$ whenever it was before. But in those cases in which it used to be $\$ 10.00$, it is sometimes $\$ 10.00$ and sometimes $\$ 9.00$. (It is $\$ 9.00$ about 8 percent of the time.) The additional variability comes when speculators buy in one period in the hope of a huge price rise and then, disappointed in the next period, dump their holdings. Note that only very rarely will their storage decision look sensible ex post. But it is perfectly rational ex ante because, if it is "right," it gives a huge rate of return.

The reader will doubtless note the extent to which we have cooked this example. We wished to present as stark an example as possible of price destabilization (and one that will be an example of destabilization under any reasonable notion of that term). Perfectly elastic consumption demand and a sharp cutoff (at 50 units) of the storage capabilities of speculators were the keys. Relaxing these would muddy the waters considerably: Storage activities would help depress the very high prices if demand were less than perfectly elastic at $\bar{\theta}$. And either competition among speculators or reduced supplies for consumption (or both) would raise prices when speculators are withdrawing supplies for purposes of storage. We do not mean to suggest that speculation must destabilize prices. But this example clearly shows that, in a model that plays by all the rules of rationality and competitive agents, speculation may have this effect.

Moreover, we contend that this example may well capture salient aspects of reality. Think of the $\theta_{t}$ process not as an i.i.d. sequence but as a process that very occasionally flips from one state to the other. We have in mind some very rare but very significant sea change in the structure of the economy: war, famine, or a very radical change in climate or technology. Such sea changes are often heralded in the press as being imminent. In fact, the heralds appear much more often than the changes, followed by heralds of some different and radical change. That is, these premonitions of change are wrong more often than not, but they do indicate that one is in a period in which the sea change, very unlikely (in the short run) in any case, is relatively more likely. This increase in the likelihood of the change, especially if the change is massive, may be enough to cause speculators to enter whatever markets are appropriate. Then, as is almost always the case, the premonitions turn out to have been wrong, the danger recedes, and speculators dump their holdings, depressing prices. Especially where the change is of the extremely rare and extremely catastrophic variety, one might observe a large number of episodes of price fluctuations and no observable (ex post) reason for these fluctuations.

This is simply a recasting of the so-called peso problem, studied by 
Krasker (1980), in which the peso forward rate fluctuated in anticipation of a devaluation that did not come. It provides a possible explanation for the recent empirical work on the volatility of share prices (e.g., Shiller 1981a). The empirical finding is that share prices fluctuate too much given the observed fluctuations in the net present value of dividends. If some changes in dividends are of the extremely large and rare variety, however, one may require many years of data for these to show up. These changes, although rarely observed (perhaps not yet observed at all), may still cause fluctuations in share prices, given the sorts of imperfect portents that we have in mind. ${ }^{1}$

In the rest of the paper, we shall investigate in greater depth what drives the example above. To put it another way, we shall consider conditions that are sufficient to rule out the destabilizing speculation of this example. These conditions will turn out to be surprisingly strong.

We will do everything possible to avoid discussing the welfare implications of speculation, and this simple example is useful for saying why this is. In this example, the speculators are risk-neutral expected consumption maximizers. Because of the constraint that they face in their storage capacity, even though they are competitive, they extract positive surplus from being allowed to engage in speculation. And the consumers are better off for the presence of the speculators, at least if one uses the expected consumer surplus measure. So even though prices are less stable, welfare of the consumers and speculators is Pareto-improved.

However, some party is supplying those fresh 100 units each period, and they, it might be supposed, are worse off for sometimes getting $\$ 9.00$ for their output when previously they got $\$ 10.00$. If we think of the supply as coming in the form of endowment to the speculators, then with the storage constraint we have imposed they are still better off (ex ante) if they are allowed to speculate. But if the 100 units come from some third sector of, say, consumers of the numeraire good and if members of this third sector are extraordinar-

\footnotetext{
${ }^{1}$ This would be one sort of small sample bias. Others are discussed in Kleidon (1986). Also, it should be noted that Shiller himself $(1981 b$, p. 300) considers and rejects this explanation of his empirical findings. We do not wish to enter into any empirical controversy, but we cannot help noting that if we interpret $\theta_{t}=\bar{\theta}$ as Shiller's disaster and the time period as 1 year, then our numbers work out as follows. There is a .01 chance of a disaster in any year, the chance of observing no disasters in a period of 108 years is approximately .34 , and the chance of observing exactly one disaster is around .37. Moreover, the standard deviation in the probability that a disaster will occur next period is approximately .03 . This is not the .05 that is needed to explain Shiller's data, but then we have not tried to find the model that maximizes the standard deviation in the probability of an incipient disaster subject to keeping the average probability of a disaster low. In any event, this explanation is not so easy to dismiss as Shiller seems to contend.
} 
ily risk averse concerning their level of consumption, then we can juggle the ex ante probabilities of being a consumer, a speculator, or a member of this third sector so that speculation leads to an ex ante Pareto decline in welfare. We repeat from the Introduction: Welfare considerations are difficult, and they may bear no particular relationship to the stability or instability of prices.

\section{A General Model}

The basic structure of the economy in our example is kept throughout: There are one-period consumers, whose demand is given by the schedule $D\left(p_{t} ; \theta_{t}\right)$ and there are overlapping generations of speculators. We begin with two regularity assumptions about the demand schedules of the consumers.

Assumption 1. The possible values of $\theta_{t}$ (the possible demand schedules) are finite in number, coming from a finite set $\Theta$. Within $\Theta$ are a "least" and a "greatest" $\theta$, written $\underline{\theta}$ and $\bar{\theta}$, such that

$$
D(p ; \underline{\theta}) \leq D(p ; \theta) \leq D(p ; \bar{\theta}) \text { for all } p \text { and } \theta \in \Theta .
$$

Assumption 2. For each $\theta, D(p ; \theta)$ is strictly positive and continuously differentiable in $p$, with strictly negative derivative (for $p$ between zero and infinity). Also, $D(0 ; \theta)=\infty$ and $\lim _{p \rightarrow \infty} D(p ; \theta)=0$; the usual Inada conditions hold.

Note that, by virtue of assumption 2 , if we let $P(x ; \theta)$ be the inverse demand function, then $P$ has all the properties enumerated for $D$ in assumption 2. Note also that assumption 2 is violated in the example of Section II; however, examples "close" to the one given there can be constructed that satisfy assumption 2 and that exhibit the same behavior, although price when $\theta_{t}=\bar{\theta}$ will have to fall a bit from $\$ 1,000$.

Speculative demand at date $t$ depends on the current price $p_{t}$ and the distribution of next period's price, which we write $F_{t+1}$. This demand schedule is denoted by $D^{\prime}\left(p_{t} ; F_{t+1}\right)$. The following assumptions are made.

Assumption 3. For fixed $F_{t+1}, D^{\prime}\left(p_{t} ; F_{t+1}\right)$ is continuous and nonincreasing in $p_{t}$.

Assumption 4. For fixed $p_{t}, D^{\prime}\left(p_{t} ; F_{t+1}\right)$ is continuous and nondecreasing in $F_{t+1}{ }^{2}$

Assumption 5. If $p_{t}$ exceeds the largest value in the support of $F_{t+1}$, then $D^{\prime}\left(p_{t} ; F_{t+1}\right)=0$.

\footnotetext{
${ }^{2}$ Since $F_{t+1}$ is a distribution, this assumption needs clarification. The schedule $D^{\prime}$ is continuous in $F_{t+1}$ in the sense that, if $\left\{F^{n} ; n=1,2, \ldots\right\}$ have uniformly bounded supports and approach $F$ in the weak topology, then $D^{\prime}\left(p, F^{n}\right) \rightarrow D^{\prime}(p ; F)$ for all $p$. And $D^{\prime}$ is nondecreasing in $F_{t+1}$ if $D^{\prime}\left(p ; F^{\prime}\right) \geq D^{\prime}(p ; F)$ for all $p$ whenever $F^{\prime}$ is (first-order) stochastically larger than $F$.
} 
In other words, no one will speculate if it is certain that they will lose money by doing so.

Assumption 6. $\operatorname{Lim}_{p_{t} \rightarrow \infty} D^{\prime}\left(p_{t} ; F_{t+1}\right)=0$, uniformly in $F_{t+1}$.

That is, speculative demand falls to zero as $p_{t}$ gets large, regardless of the promises of speculative profits.

Assumption 7 . For every $\lambda>1, p_{t}$, and $F_{t+1}, D^{\prime}\left(p_{t} ; F_{t+1}\right) \geq D^{\prime}\left(\lambda p_{t}\right.$; $\lambda F_{t+1}$ ), where $\lambda F_{t+1}$ means the distribution $F_{t+1}$ "inflated" by $\lambda$. That is, $\lambda F_{t+1}(q)=F_{t+1}(q / \lambda)$.

Of our assumptions, these last two are the least palatable. (They are made so that, subsequently, we can obtain uniqueness of equilibrium.) One way to view assumption 7 is to note that, by inflating both the current price, $p_{t}$, and the distribution of next period's price, $F_{t+1}$, by the factor $\lambda$, we do not change the distribution of rates of return derived from speculation. If speculators base their demand only on the rates of return from speculation, their demand will be unchanged. Indeed, one might expect speculative demand to fall, insofar as the same rates of return prevail, but at higher stakes. (And, to satisfy assumption 6 , for large enough $\lambda$ we will have to have strict inequality.)

The simplest story underpinning $D^{\prime}$ is that each speculator possesses a storage technology of the following sort: Storage of $y$ units at date $t$ yields $f(y)$ units recovered at date $t+1$. Imagine that $f(0)=0$, $f(y) \leq y$ for all $y$, and $f$ is nondecreasing, nonnegative, strictly concave, and bounded above. Speculators are risk neutral with a zero discount rate in the sense that they attempt to maximize the expected revenue accrued from selling $f(y)$ units at price $p_{t+1}$ less the cost $p_{t} y$ of purchasing the $y$ units for storage. Thus each speculator will wish to store that quantity $y^{*}$ that satisfies $f^{\prime}(y)=p_{t} / E\left(\hat{p}_{t+1}\right)$, where $\hat{p}_{t+1}$ represents the random variable of next period's price (the distribution of which is given by $\left.F_{t+1}\right)$, and $E(\cdot)$ denotes expectation. Of course, $y^{*}$ is constrained below to be nonnegative and above by $w / p_{t}$, where $w$ is the speculator's wealth in the numeraire good, assumed to be finite and exogenously given. Then $D^{\prime}$ is just the number of firms times the optimal (constrained) $y^{*}$. The reader can easily check that assumptions $3-7$ all hold: assumption 5 because we assume that $f(y) \leq y$ and $f$ is strictly concave, assumption 6 because of the finite wealth constraint, and assumption 7 because only rates of return matter until the constraints bind, and the constraints go in the right direction.

Many variations on this simple story can be played, but care must be taken if the assumptions are to remain. One can allow speculators to borrow in the numeraire in order to finance their purchases as long as there is some limit on credit. (Otherwise, assumption 6 is in jeopardy. Such a credit limit arises from general equilibrium considerations if there is a finite amount of wealth in the economy at each date.) A 
positive discount rate or risk aversion could be added. But in adding risk aversion, one must be careful to preserve the nondecreasing part of assumption 4. (If, for example, speculators had a target level for proceeds from sales, then raising $F_{t+1}$ could lower the amount they need to store to make that target.)

Speculators base their storage decisions at date $t$ on the publicly available information $\left(\theta_{t}, \xi_{t}\right)$, which we write $\phi_{t}$, where $\xi_{t}$ represents any information that they might possess concerning future demand (beyond what is in $\theta_{t}$ ). We assume that all speculators concur in the following (objective) assessment.

Assumption 8 . The sequence $\left\{\phi_{t} ; t=\ldots,-1,0,1, \ldots\right\}$ forms a time-homogeneous Markov chain with finite state space $\Phi .{ }^{3}$

Note that the $\phi_{t}$ may be serially correlated. This can occur even if the $\theta_{t}$ are uncorrelated or independent because of the additional information $\xi_{t}$. For example, if $\xi_{t}=\theta_{t+1}$, then $\phi_{t}=\left(\theta_{t}, \theta_{t+1}\right)$ and $\phi_{t+1}=$ $\left(\theta_{t+1}, \theta_{t+2}\right)$ are dependent.

All that remains is to specify the supply side of the economy. Supplies in period $t$, denoted $X_{t}$, are inelastic and depend on the amount stored in the previous period. That is,

$$
X_{t+1}=G\left(D^{\prime}\left(p_{t} ; F_{t+1}\right)\right)
$$

for a given function $G$. For example, in our simple storage story,

$$
G\left(D^{\prime}\left(p_{t} ; F_{t+1}\right)\right)=\underline{X}+n f\left(\frac{D^{\prime}\left(p_{t} ; F_{t+1}\right)}{n}\right),
$$

where $X$ is exogenous supply each period, and $n$ is the number of speculators. The following general assumption is made.

Assumption 9. The function $G$ is nondecreasing and continuous, and it satisfies $G(0)>0$ and $\lim _{y \rightarrow \infty} G(y)<\infty$. Also, $G(y)-G(0) \leq y$ for $y$ $\geq 0$.

The last part simply says that storage is nonproductive. ${ }^{4}$

In summary, our market model is determined by equation (1) and the supply equals demand equation,

$$
X_{t}=D\left(p_{t} ; \theta_{t}\right)+D^{\prime}\left(p_{t} ; F_{t+1}\right) .
$$

These are subject to assumptions $1-9$ above.

\footnotetext{
3 Time homogeneity simply means that transition probabilities from one state to another do not depend on calendar time.

'We note again that, since supply is inelastic and demand is independent of the amount brought forward, we are thinking of a consumption sector distinct from storers and from overlapping generations of speculators who consume only the numeraire. Random exogenous supply is easily accommodated by shifting any randomness to the demand side, i.e., by absorbing it in $D$. Randomness in the storage technology can also be accommodated, although the model becomes a bit more complicated.
} 
Before giving a formal definition of equilibrium, let us briefly sketch a second interpretation of our model involving durable goods. Think of a market for houses in a given locality. In this locality is a fixed stock $Y$ of houses, subject to no depreciation. At date $t$ some part of this stock, say $Y_{t}$, is held by owner-occupiers (consumers). A randomly selected fraction $\alpha$ of these consumers are compelled by circumstances (death, a job somewhere else) to sell their houses-the stock that they own $\left(\alpha Y_{t}\right)$ is inelastically supplied to the market. These departing consumers are replaced by an equal number of new consumers (new families, people taking jobs in the area) so that the number of consumers is constant. (This is not a one-house-per-consumer society; per capita holdings of the asset will change through time. Think of it this way: Some of the consumers own houses, while others, finding the price of housing too high on arrival, decide to rent accommodation.) Newly arrived consumers demand houses in a fashion that depends on the current price $p_{t}$ and a random taste parameter $\theta_{t}$; this gives us $D$. Also, there are speculators who buy the houses one period and sell them the next. Imagine that these speculators live for two periods only, so their supply (at the end of their lives) is inelastic. Their demand (at the beginning of their lives) depends on the current price and the distribution of next period's price; this gives us $D^{\prime}$. Equation (2) is immediate. As for (1), since consumers hold what speculators do not,

$$
X_{t+1}=G\left(D^{\prime}\left(p_{t} ; F_{t+1}\right)\right)=D^{\prime}\left(p_{t} ; F_{t+1}\right)+\alpha\left[Y-D^{\prime}\left(p_{t} ; F_{t+1}\right)\right] .
$$

In this interpretation, we assume that owner-occupiers do not enter the housing market except when they first arrive and when they depart; they do not adjust their holdings in the intervening periods. Also, they are, on arrival, sensitive only to current price; they ignore the possible capital gains in deciding how much to demand. We are able to make some excuses for these assumptions: Transaction costs for owner-occupiers are too high to make retrading profitable. Capital markets are imperfect so that utility from capital gains is nearly inconsequential, or utility from capital gains is logarithmic (so that while capital gains do affect utility levels, demand is insensitive to future prices). The fact that such imperfections must now be assumed, however, means that this interpretation of the model is not as clean as the interpretation involving a commodity.

\section{Equilibrium}

Fix the data of a model as in Section III. Let $\bar{X}=\lim _{y \rightarrow \infty} G(y)$ and $X=$ $G(0)$ (i.e., supplies in any period lie somewhere between $\bar{X}$ and $X$ ). The equilibrium price $p_{t}$ will be a function of current information $\phi_{t}$ and 
current supplies $X_{t}$. We will look for time-homogeneous equilibria: $p_{t}$ does not depend on the particular value of $t$. Hence, we look for prices given by some function $p$ from $\Phi \times[X, \bar{X}]$ into $[0, \infty)$. Imagine that some such function $p$ is advanced as a candidate for an equilibrium. When the current state of information is $\phi=(\theta, \xi)$ and supplies are $X \in[X, \bar{X}]$, consumption demand (at the supposed equilibrium price) will be $D(p(\phi, X) ; \theta)$. Storage in equilibrium will therefore be the residual of supply, or $X-D(p(\phi, X) ; \theta)$. This means that supply next period will be $G(X-D(p(\phi, X) ; \theta))$. Thus the distribution of next period's price (still assuming that the function $p$ gives equilibrium prices) will be the distribution of

$$
p\left(\hat{\phi}_{t+1}, G(X-D(p(\phi, X) ; \theta))\right) \text { given } \phi_{t}=\phi,
$$

where $\hat{\phi}_{t+1}$ is random. Let us write

$$
F(\phi, G(X-D(p(\phi, X) ; \theta)), p)
$$

for this distribution function. Note how the three arguments enter: $\hat{\phi}_{t+1}$ is distributed according to the Markov transition probabilities, given $\phi_{t}=\phi$; the second argument gives the supplies brought forward into next period; and $p$ gives the (supposed) equilibrium price functional.

The equilibrium condition is that speculative demand does indeed absorb the residual of supply less consumption demand. This yields the following formal definition.

Definition. An equilibrium is a function $p: \Phi \times[\underline{X}, \bar{X}] \rightarrow[0, \infty)$ such that for every $\phi=(\theta, \xi)$ and $X \in[\underline{X}, \bar{X}]$,

$D(p(\phi, X) ; \theta)+D^{\prime}(p(\phi, X) ; F(\phi, G(X-D(p(\phi, X) ; \theta)), p))=X$.

Note that this is a rational expectations equilibrium in which speculators act competitively. That is, the speculators correctly anticipate next period's equilibrium prices, and they take as given the total amount that will be stored this period.

Proposition 1. Under our assumptions, there exists a unique equilibrium price function, which we denote $p^{*}$. This function is continuous and strictly decreasing in its second argument. (Price is lower the greater is supply.) In this equilibrium, $x-D\left(p^{*}(\phi, x) ; \theta\right)$ is increasing in $x$. (The more that is stored in one period, the more will be stored in the next, ceteris paribus.)

The proof of proposition 1 is left to the Appendix. But some short technical points about the proof that have economic relevance are worth making. Our method of proof is somewhat different from those that have appeared in the literature. As in Kohn (1978), we essentially compute the equilibrium by successively computing equilibria in which there are no speculators, then in which speculators 
will exist for only one period more, then two, and so on. In the limit, we get the equilibrium. Kohn (1978) gets convergence by a contraction mapping argument; this requires strong assumptions on elasticities. We avoid those assumptions by invoking assumption $4:$ speculative demand is nondecreasing in next period's prices. This allows us to use monotone mappings (instead of contraction mappings); prices computed for an economy in which there are $n+1$ more generations of speculators are always at least as high as in an economy in which there are $n$ more generations, with the level of current supplies held fixed. ${ }^{5}$ Because we use iterated mappings, it is (in principle) possible to compute equilibria. Also, much of the literature assumes that the $\theta_{t}$ are i.i.d. and no further information is available; we are able to avoid this entirely. Typically, it is difficult to prove uniqueness in models of speculation because of the existence of Ponzi schemes. We have avoided such schemes in two steps. First, assumption 6 rules out the possibility that equilibrium prices will become unbounded. And then assumptions 4 and 5 combine to rule out bounded Ponzi schemes: speculative demand must be nearly zero when prices are close to their maximum attainable value.

Indeed, we can calculate that maximum price. Let $\bar{p}$ be the solution of $D(p ; \bar{\theta})=X$. That is, $\bar{p}$ is the price that prevails if supply is $X$ (the lowest possible level), the consumption demand is at its highest possible level, and there is no speculative demand.

Proposition 2. $p^{*} \leq \bar{p}$, and for all $\xi, p^{*}((\bar{\theta}, \xi), X)=\bar{p}$.

Since we are more interested in examples than in general properties of the equilibrium, we will desist from further general development. But it is perhaps worth noting that standard results from the theory of Markov chains will (with mild regularity conditions on $G$ ) ensure that the chain $\left\{\left(\theta_{t}, X_{t}\right) ; t=0,1, \ldots\right\}$ will settle down to a longrun stationary distribution if we assume that the chain $\left\{\theta_{t}\right\}$ is well behaved (i.e., is aperiodic and irreducible).

\section{Cases of (Weakly) Stabilizing Speculation}

Were there no speculators, the evolution of the economy would be simple. Supplies at each date would be $X=G(0)$, and the equilibrium price would be a function of $\theta_{t}$, the solution to $D\left(p ; \theta_{t}\right)=X$. Let us denote this solution by $p^{c}\left(\theta_{t}\right)$ or, for $\phi_{t}=\left(\theta_{t}, \xi_{t}\right), p^{c}\left(\phi_{t}\right)$. Note that $\bar{p}$ is simply $p^{c}(\bar{\theta})$. We said above that price functions rise the longer (it is

${ }^{5}$ The force of assumption 4 should not be underestimated. If speculative demand arises from expected utility maximization, then it need not be nondecreasing in next period's prices; compare the comments concerning risk aversion following assumption 7 . 
supposed) that speculators are around. The prices $p^{c}$ correspond to an economy in which there will be no speculators in the future. Hence one might conclude that speculators only raise prices. But, of course, this is wrong. The monotonicity result holds for a fixed level of current supplies. When we add speculators, the distribution of supplies changes: speculators shift supplies; in periods in which they increase $X_{t}$, they may drive down prices. Indeed, we know already (proposition 2) that $p^{*} \leq \bar{p}^{6}$

We are interested in comparing $p^{*}$ with $p^{c}$. We saw in Section II that there exist nonpathological economies for which $p^{*}$ is more variable than $p^{c}$ under any reasonable notion of variability. One particular property of the example is that the lowest price in the support of $p^{*}$ is lower than the lowest price in the support of $p^{c}$. We now present sufficient conditions for $p^{*}$ not to be more variable than $p^{c}$ in this very grossest of senses. That is, we provide conditions for the lowest price in the presence of speculators to be greater than or equal to the lowest price in their absence. By virtue of proposition 2, this implies that the range of prices does not grow with the addition of speculators. In this case, we say that speculation is weakly stabilizing, with maximal possible emphasis on "weakly."

One case in which speculation is weakly stabilizing is the following. Suppose that $\phi_{t}=\theta_{t}$ and that the $\theta_{t}$ are i.i.d. That is, at date $t$ agents know nothing that improves on their ex ante prediction of $\theta_{t+1}$. Then given any level of $X_{t}$, the distribution of next period's prices is almost independent of the current price, and speculative demand will be larger the lower is the current price. Note well the qualifier "almost"; for fixed $X_{t}$ a larger speculative demand this period means lower prices next (through the effect on $X_{t+1}$ ). The point is that the "buycheap-sell-dear" adage (which gives us hope for price stabilization) does hold at the equilibrium.

Lemma. In the special case $\phi_{t}=\theta_{t}$ and $\left\{\theta_{t}\right\}$ an i.i.d. sequence, if $p^{*}(\theta$, $X)>p^{*}\left(\theta^{\prime}, X\right)$, then $D\left(p^{*}(\theta, X) ; \theta\right) \geq D\left(p^{*}\left(\theta^{\prime}, X\right) ; \theta^{\prime}\right)$.

We have stated the results in terms of $D$ instead of $D^{\prime}$. The reverse inequality holds for $D^{\prime}$. Suppose we strengthened assumption 1 so that the possible values of $\theta$ were real numbers, and higher $\theta$ meant a consumption-demand curve that was shifted up and to the right. Then this lemma could be paraphrased: Those consumers who value

\footnotetext{
${ }^{6}$ It is easy to show that, with speculators, prices arbitrarily close to $\bar{p}$ will be observed infinitely often, regardless of the initial conditions, as long as $\bar{\theta}$ is visited infinitely often (is positively recurrent from every other state) and transition from $\bar{\theta}$ to $\bar{\theta}$ in a single step has positive probability. (This will be true in all our examples.) This is because, however large are initial stocks, if there are sufficiently many high-demand states in a row (an event that will occur eventually), these stocks will be exhausted and prices will rise to $\bar{p}$. (In this regard, note our assumption that the level of stocks is bounded above.)
} 
the good more highly get more of it. This paraphrase is precise: Since $X_{t}$ is a function of $X_{0}$ and $\left\{\theta_{t-k} ; k \geq 1\right\}, X_{t}$ is independent of $\theta_{t}$.

To show this, suppose the converse held. Then supplies next period would be higher under $\theta$ than $\theta^{\prime}$, implying that next period's price will be lower under $\theta$. Thus, since $p^{*}(\theta, X)>p^{*}\left(\theta^{\prime}, X\right)$, speculative demand is lower under $\theta$, which is a contradiction.

Does the fact that the adage holds mean that speculators stabilize prices weakly? Proposition 3 says that the answer is yes.

Proposition 3. In the special case $\phi_{t}=\theta_{t}$ and $\left\{\theta_{t}\right\}$ i.i.d., if we begin with $X_{0}=X$, then $p^{*}\left(\theta_{t}, X_{t}\right) \geq p^{c}(\underline{\theta})$ for all $t$ with probability one.

To prove this, note three facts already shown. (a) In this special case, $p^{*}(\theta, x) \geq p^{*}(\theta, x)$ for all $x$. This follows from the lemma. (b) In this case, $D\left(p^{*}(\theta, x) ; \theta\right) \geq D\left(p^{*}(\theta, x) ; \theta\right)$. This is (virtually) the lemma. (c) The function $x-D\left(p^{*}(\theta, x)\right.$; $\left.\theta\right)$ is increasing in $x$. This is part of proposition 1 .

Now let $\theta_{0}, \theta_{1}, \ldots, \theta_{t-1}$ be any sequence of $\theta^{\prime}$ 's and let $X_{t}\left(\theta_{0}, \ldots, \theta_{t-1}\right)$ be defined iteratively by $X_{0}=X$ and $X_{s+1}\left(\theta_{0}, \ldots, \theta_{s}\right)=G\left(X_{s}\left(\theta_{0}, \ldots\right.\right.$, $\left.\left.\theta_{s-1}\right)-D\left(p^{*}\left(\theta_{s}, X_{s}\left(\theta_{0}, \ldots, \theta_{s-1}\right)\right) ; \theta_{s}\right)\right)$. That is, $X_{t}$ gives the value (in equilibrium) of supplies at date $t$ as a function of past states of demand, where $X_{0}=X$. We claim that, for all $\left(\theta_{0}, \ldots, \theta_{t-1}\right), X_{t}\left(\theta_{0}, \ldots\right.$, $\left.\theta_{t-1}\right) \leq X_{t}(\theta, \ldots, \underline{\theta})$ (where in the right-hand side there are $t \underline{\theta}$ 's). This follows inductively from facts $b$ and $c$. Suppose that $X_{s}\left(\theta_{0}, \ldots, \theta_{s-1}\right) \leq$ $X_{s}(\underline{\theta}, \ldots, \underline{\theta})$. Then

$$
\begin{gathered}
X_{s}\left(\theta_{0}, \ldots, \theta_{s-1}\right)-D\left(p^{*}\left(\theta_{s}, X_{s}\left(\theta_{0}, \ldots, \theta_{s-1}\right)\right) ; \theta_{s}\right) \\
\quad \leq X_{s}(\underline{\theta}, \ldots, \underline{\theta})-D\left(p^{*}\left(\theta_{s}, X_{s}(\underline{\theta}, \ldots, \underline{\theta})\right) ; \theta_{s}\right)
\end{gathered}
$$

by fact $c$

$$
\leq X_{s}(\underline{\theta}, \ldots, \underline{\theta})-D\left(p^{*}\left(\underline{\theta}, X_{s}(\underline{\theta}, \ldots, \underline{\theta})\right) ; \underline{\theta}\right)
$$

by fact $b$. Since $G$ is nondecreasing, we obtain $X_{s+1}\left(\theta_{0}, \ldots, \theta_{s}\right) \leq X_{s+1}(\underline{\theta}$, $\ldots, \underline{\theta}$ ), completing the induction step. Thus

$p^{*}\left(\theta_{t}, X_{t}\left(\theta_{0}, \ldots, \theta_{t-1}\right)\right) \geq p^{*}\left(\theta_{t}, X_{t}(\underline{\theta}, \ldots, \underline{\theta})\right) \geq p^{*}\left(\underline{\theta}, X_{t}(\underline{\theta}, \ldots, \underline{\theta})\right)$.

(The last step uses fact $a$.) Thus the lowest possible price at date $t$ is the one at which every $\theta_{s}=\underline{\theta}$.

And, finally, if we start at $X_{0}=X$, then $X_{1}(\underline{\theta}) \geq X_{0}$. Applying fact $c$ inductively shows that $X_{t}(\underline{\theta}, \ldots, \underline{\theta}) \geq X_{t-1}(\underline{\theta}, \ldots, \underline{\theta})$. Thus along the sequence $\theta_{0}=\theta, \theta_{1}=\underline{\theta}, \ldots$, if we start at $\overline{X_{0}}=\underline{X}$, then prices continually decline. $\overline{\mathrm{B}}$ ut they can never decline below $p^{c}(\underline{\theta})$, since at each stage speculative demand is at least as large as at the stage before, and so $G\left(D_{t}^{\prime}\right)-D_{t+1}^{\prime} \leq G\left(D_{t}^{\prime}\right)-D_{t}^{\prime} \leq G(0)$. Thus price is such that consumption demand is no more than $G(0)$; that is, price is no lower than $p^{c}(\underline{\theta})$. 
Is there any stronger criterion by which one might judge the stability of prices? One possibility is to look at the stationary distribution of prices, using summary statistics such as the variance of the distribution or criteria of riskiness such as those in Rothschild and Stiglitz (1970) or Diamond and Stiglitz (1974). But consider: Suppose that in one regime we have price equal to $\$ 100$ for 1,000 periods in a row, followed by 1,000 periods at $\$ 200$, then 1,000 at $\$ 100$, and so forth, while in a second regime the price is either $\$ 101$ or $\$ 199$, each with probability one-half, independent of previous prices. By criteria applied to the distribution of prices, the former regime is "less stable," yet this does not necessarily accord with our intuition. So perhaps we should look at the stationary distribution of price changes (in either absolute or relative terms): we could consider the variance of price changes or apply Diamond-Stiglitz or Rothschild-Stiglitz measures to them.

It is hard to find some criterion by which one might choose because greater stability is not related to anything like the welfare of consumers or any other economically meaningful quantity. We can think of circumstances in which each of these measures would be appropriate and others in which each would be inappropriate, at least intuitively. (The example of Sec. II, it should be noted, gives greater instability in both the distribution of prices and the distribution of price changes.) And, in any event, even when $\phi_{t}=\theta_{t}$ and the $\theta_{t}$ are i.i.d., it seems unlikely that any stronger results can be obtained.

One problem is the following: Consider what happens if some of the good put into storage is lost to wastage. In this case, average consumption with speculation will be less than average consumption without, so one expects average prices to rise. This is rigorously true if $D(p ; \theta)=K(\theta)-A p$ for constant $A>0$ in the relevant range of prices. How does a rise in average price square with greater stability? If, moreover, demand at $\underline{\theta}$ is (nearly) perfectly elastic (and the storage capacity of speculators is insufficient to absorb $\underline{X}$ ), then correcting for any such shift in mean will give a (corrected) distribution of prices under speculation that falls below the distribution of prices for the economy with no speculation. ${ }^{7}$ What about the distribution of price changes? We will not give details but simply assert that examples can be constructed that show that the answer here is ambiguous as well. If a stronger statement than the proposition is possible, we do not know what it is.

Since it is hard to strengthen the notion of stabilization, we now consider whether instead it is possible to relax the conditions required

\footnotetext{
${ }^{7}$ Wright and Williams (1982) note the difficulty of determining whether speculation is stabilizing given a change in the average price.
} 
for stabilization. In the example of Section II, the sequence $\left\{\theta_{t}\right\}$ is i.i.d. Hence this alone is insufficient for the weak result in proposition 3 if agents are able to foresee something of the future. It is also insufficient to assume that $\phi_{t}=\theta_{t}$ but relax the assumption that $\left\{\theta_{t}\right\}$ is i.i.d. This is immediate from the example of Section II as well: we can simply redefine $\theta_{t}$ so there are four possible values corresponding to the four states in the Markov chain.

One might imagine that what causes the problem in the example is the imperfect nature of the signal $\xi_{t}$. Suppose, for example, that $\left\{\theta_{t}\right\}$ is i.i.d. and that any foreseeing that takes place is flawless: $\phi_{t}=\left(\theta_{t}, \theta_{t+1}\right.$, $\ldots, \theta_{t+k}$ ) for some $k$. Will this suffice to obtain a result analogous to proposition 3 ?

The answer is no, for any finite $k$. Fixing $k$, we can construct an example in which the lowest price with speculation is lower than the lowest without. Let us sketch the example for $k=1$ to give the basic idea.

Imagine that $\theta_{t}$ can take on any of three values, $\underline{\theta}, \theta^{0}$, or $\bar{\theta}$. Consumption demand schedules are as illustrated in figure 1. Suppose

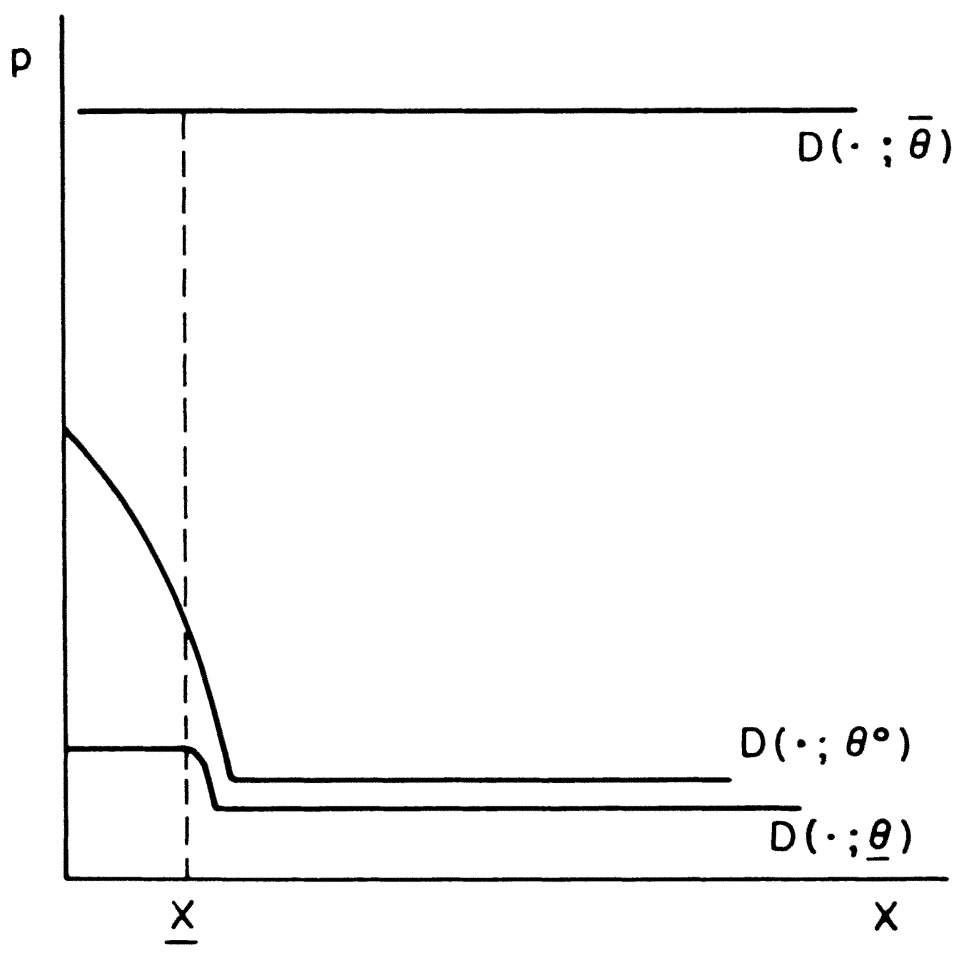

Fig. 1 
that $\bar{\theta}$ has very high probability and that $D(\cdot ; \bar{\theta})$ is sufficiently high that, whenever it is known that $\theta_{t+1}$ will equal $\bar{\theta}$, speculators buy up to their capacity (less than $X$ ). Moreover, the chance that $\theta_{t+2}=\bar{\theta}$ is so high that, when $\theta_{t+1}=\bar{\theta}^{0}$ and $\theta_{t}=\underline{\theta}$, the anticipation of this (and the concomitant rise in $p_{t+1}$ ) causes speculators to buy up to their capacity. But when $\theta_{t+1}=\underline{\theta}$, the elasticity of $D(\cdot ; \underline{\theta})$ implies that in period $t+1$ prices will not rise above $p^{c}(\underline{\theta})$; hence under no circumstances would speculators store at date $t$.

Start the economy with $\theta_{t}=\underline{\theta}$ and $\theta_{t+1}=\theta^{0}$. Speculators then store, anticipating that, with high probability, $\theta_{t+2}$ will equal $\bar{\theta}$ and $p_{t+1}$ will rise, given the further rise anticipated at date $t+2$. But then suppose $\theta_{t+2}$ turns out to be $\theta$. Speculators will dump their stores, and-the way we have drawn $\bar{D}\left(\cdot ; \theta^{0}\right)$-this will take $p_{t+1}$ below $p^{c}(\theta)$. Note that prices will never fall below $p^{c}(\theta)$ when $\theta_{t}=\theta$, but they will sometimes do so when $\theta_{t}=\theta^{0}$. That is, the lowest observed price will not correspond to the lowest $\theta$.

This covers the case $k=1$. For any finite $k$, a similar example can be constructed by having the consumption demand curves ever more wild in behavior. On the other hand, if we fix an economy except for the specification of $k$ (i.e., fix $D, D^{\prime}, \Theta$, and $G$ ) and then lengthen the foresightedness of agents by increasing $k$, eventually we get an asymptotic result analogous to proposition 3 . Indeed, for cases of very far foresightedness, we need not assume that the $\theta_{t}$ are i.i.d.

While the general proof (and even the statement of the result) is quite involved, there is a simple limiting case, that of perfect foresight: At date $t$ agents know all future values of $\theta_{t+k}$. (This violates our assumption of finite $\Phi$; however, no technical problems arise.)

Proposition 4. In the case of perfect foresight (starting with $X_{0}=$ $\underline{X})$, equilibrium prices never drop below $p^{c}(\theta)$.

The proof is simple. Fix any sequence $\left\{\theta_{t}\right\}$, and let $p_{0}, p_{1}, \ldots$ be the (deterministic) sequence of equilibrium prices. Suppose (inductively) that $p_{t} \geq p^{c}(\underline{\theta})$. Either $p_{t+1} \geq p_{t}$ or $p_{t+1}<p_{t}$. In the former case, $p_{t+1} \geq$ $p^{c}(\theta)$. And in the latter case, speculative demand is zero so that $p_{t+1} \geq$ $p^{c}\left(\bar{\theta}_{t+1}\right) \geq p^{c}(\underline{\theta})$. Since $p_{0} \geq p^{c}(\underline{\theta})$, the result follows by induction.

More generally, we have the following result.

Proposition 5. Fix the following pieces of a model: $\Theta, D, D^{\prime}$, and $G$. For every $\epsilon>0$ there exists an $N$ such that for all models in which $\phi_{t}$ reveals (at least) $\left(\theta_{t}, \theta_{t+1}, \ldots, \theta_{t+N}\right)$, the lowest price ever achieved, starting with $X(0)=\underline{X}$, is greater than or equal to $p^{c}(\theta)-\epsilon$.

The proof is only sketched here. (A complete proof is available from the authors on request.) Given our assumptions, one can show that for every $\delta>0$ there is a sufficiently large $N$ (depending on $\Theta, D$, $D^{\prime}$, and $G$ ) that, if agents can foresee at least $N$ periods, the support of prices next period is contained in an interval of size $\delta$. That is, as one 
sees further and further into the future, surprises about that future have less and less effect on next period's prices. Now for every $\epsilon>0$, there is a $\beta>0$ such that prices can be depressed to a level at or below $p^{c}(\underline{\theta})-\epsilon$ only if supplies carried forward by speculators are at least $\beta$. And for each $\beta>0$ there is a "rate of interest" $\iota>0$ such that speculators will not carry forward $\beta$ unless there is positive probability that prices will rise by at least $\iota$. If we take $\delta$ to be $\iota\left[p^{c}(\underline{\theta})-\epsilon\right] / 2$ and $N$ sufficiently large, this means that prices can be depressed to below $p^{c}(\theta)-\epsilon$ from above this level only if they are certain to be no lower than $p^{c}(\theta)-\epsilon$, which establishes $p^{c}(\underline{\theta})-\epsilon$ as a lower bound if we start above this level.

\section{Concluding Remarks}

It is sometimes argued that speculation has the following desirable features. First, by buying cheap and selling dear, speculators stabilize prices. Second, by looking into the future and anticipating economic trends, speculators smooth the transition of the economy from one long-run equilibrium to another. We have shown, using a very simple model in which speculation is synonymous with storage, that speculation may possess neither of these features. In particular, we have presented examples in which, in spite of the fact that nonspeculators and speculators alike behave rationally and speculators are competitive, speculation destabilizes prices (in any meaningful sense of the word). Moreover, this is not because of a lack of foresight by speculators: in fact, making speculators more foresighted may actually worsen the problem.

As we have emphasized, the conclusion is that speculative activity may destabilize prices, not that it will. In fact, we have presented sufficient conditions for speculation to be stabilizing (albeit in a very weak sense). These are that consumption demand is independently and identically distributed over time and that speculators have no foresight about future demand at all, or that speculators have a great deal of foresight. The extreme restrictiveness of these conditions is striking, as is the very weak criterion of stabilization that we can show. And it is not lack of effort (at least) that causes us to report such meager positive results.

Indeed, while we do not believe that speculative activity has no stabilizing effect at all, we do find appealing the sort of short-run decrease in stability that permeates our basic example. Speculators will buy or sell according to increases and decreases in the probability of large-scale changes. They may withdraw supplies from the market, and then, when the danger recedes, they may dump those supplies back on the market. While this activity might well smooth the major 
transitions when they happen, it can (and, we believe, does) do so at the cost of more small-scale fluctuations for which a tangible cause will only very rarely be identifiable.

In order to proceed with our analysis, we have made a number of simplifying assumptions. One of the most serious of these is the omission of production. It is not clear, however, that including production would change our conclusions all that much. One must take care in distinguishing between instantaneous production and production with a lag. If production is instantaneous, then it can be absorbed into nonspeculative demand, and our analysis is unaltered. Production with a lag raises new issues. Production with a lag (of, say, one period) is similar to storage in some respects, but there is an important difference: Storage responds (generally) to increased chances for spot price appreciation since the opportunity cost of storage is forgone consumption today of the good in question. Insofar as production has as opportunity cost forgone consumption of other goods, it responds more to increased chances of high (absolute) prices tomorrow. This can have counterintuitive effects (see, e.g., Scheinkman and Schechtman 1983). Still, the sort of example we have given for destabilizing storage is easily modified to give an example of destabilizing production. At the same time, with lagged production, speculation may yield an important additional benefit of conveying information. Suppose, for example, that speculators (correctly) anticipate a future increase in demand for a commodity. This will increase current storage demand and hence lead to a current price rise. Producers, observing this price rise, will, given rational expectations, deduce that future demand is likely to be high and will be encouraged to invest in the future production of the commodity. As a result, future prices will be lower than otherwise (since supplies are greater), and the price path may be stabilized relative to a situation of no speculation. (This, of course, is subject to exactly the sorts of caveats around which this paper has been written.) Thus the inclusion of production may strengthen the case that (foresighted) speculative activity is stabilizing, at least insofar as it gives to producers information that they would otherwise not collect.

Finally, we should emphasize that (as already noted in the Introduction), while we have studied the effect of speculation on prices, the more interesting economic question concerns the effect of speculation on welfare. Conditions are known under which competitive speculation leads to a first-best in terms of total welfare (see, e.g., Samuelson 1971; Scheinkman and Schechtman 1983). This is so regardless of whether speculation stabilizes or destabilizes prices. But these conditions involve risk neutrality, and they are results for total welfare. We noted, in the context of our basic example, that with risk- 
averse producers, "destabilizing" speculation can lead to an ex ante Pareto decrease in utility. Examples in the spirit of Newbery and Stiglitz (1984) can obtain the same result for "stabilizing" speculation. And if one looks at one sector only and not at overall welfare, then even assuming risk neutrality is of little help. In our basic example, consumers are better off for having prices destabilized; and it is not hard to put together examples in which risk-neutral consumers are worse off with (stabilizing) speculation. We have shown here that it is hard to say much about the effects of speculation on price stability. It is just as hard to say anything about the welfare implications of speculation.

\section{Appendix}

\section{Technical Details}

Recall that $\bar{p}$ solves $D(\bar{p}, \bar{\theta})=X$. Let $\underline{p}$ be the solution to $D(p, \underline{\theta})=\bar{X}$. By assumption 2, there exists a constant $\gamma$ such that, for each $\bar{\theta}, \bar{D}(\cdot ; \theta)$ is $\gamma$ Lipschitzian over the range $[p, \bar{p}]$ and $P(\cdot ; \theta)$ is $\gamma$-Lipschitzian over the range $[\underline{X}, \bar{X}]$. (Take $\gamma$ to be a uniform upper bound on the first derivatives of the functions over these compact intervals.)

Lemma Al. Suppose that $q: \Phi \times[X, \bar{X}] \rightarrow[0, \infty)$ is continuous and nonincreasing in its second argument and that $q \leq \bar{p}$. Then there exists a unique function $T q: \Phi \times[\underline{X}, \bar{X}] \rightarrow[0, \infty)$ that solves

$$
D(T q(\phi, X) ; \theta)+D^{\prime}(T q(\phi, X) ; F(\phi, G(X-D(T q(\phi, X) ; \theta)), q))=X .
$$

Moreover, this function $T q$ is strictly decreasing and $2 \gamma$-Lipschitzian in its second argument and satisfies $\underline{T} \leq T q \leq \bar{p}$.

The operator $T$ defined by (Al) has a simple interpretation: If prices next period are given by $q$ and if speculators this period understand that this is so, then prices this period are given by $T q$.

Proof. Refer to figure Al. Fixing $\phi=(\theta, \xi)$ and $X$, we graph $D(p ; \theta)$ and $D(p ; \theta)+D^{\prime}(p ; F(\phi, G(X-D(p ; \theta)), q))$. Of course, $D(p ; \theta)$ is continuous and strictly decreasing in $p$. And $D^{\prime}(p ; F(\phi, G(X-D(p ; \theta)), q))$ is continuous and nonincreasing in $p$. To see that $D^{\prime}$ is nonincreasing, note that increasing $p$ raises the first argument and lowers (stochastically) the second. As for continuity, apply assumptions 3,4 , and 9 , noting that $q$ is, by assumption, bounded above. For $p \leq p, D(p ; \theta)$ and, hence, $D+D^{\prime} \operatorname{exceed} \bar{X}$. For $p \geq \bar{p}, D(p ; \theta) \leq \underline{X}$ while $D^{\prime}=0$ (since $q \leq \bar{p}$ ), so $D+D^{\prime} \leq \underline{X}$. Thus figure Al is appropriate, and (for each $X \in[\underline{X}, \vec{X}]$ ) there exists a unique $T q(\phi, X)$ that solves equation (Al) and that lies between $\underline{p}$ and $\bar{p}$.

Refer now to figure A2. Fixing $\phi=(\theta, \xi)$, when we raise $X$ to the level $X^{\prime}$, the level of $D^{\prime}$ falls for each $p$ because $X-D(p ; \theta)$ and, hence, $G(X-D(p ; \theta))$ both increase, which causes the distribution of future prices to fall. It is immediately clear that $T q\left(\phi, X^{\prime}\right)<T q(\phi, X) ; T q$ is strictly decreasing in its second argument. (The strictness comes from the strict decrease in $D$.) To measure how much $T q$ decreases, we will estimate first $p^{0}-T q\left(\phi, X^{\prime}\right)$ and then $T q(\phi, X)-p^{0}$, where $p^{0}$ is (as shown) the solution of

$$
D(p ; \theta)+D^{\prime}\left(p ; F\left(\phi, G\left(X^{\prime}-D(p ; \theta)\right), q\right)\right)=X .
$$




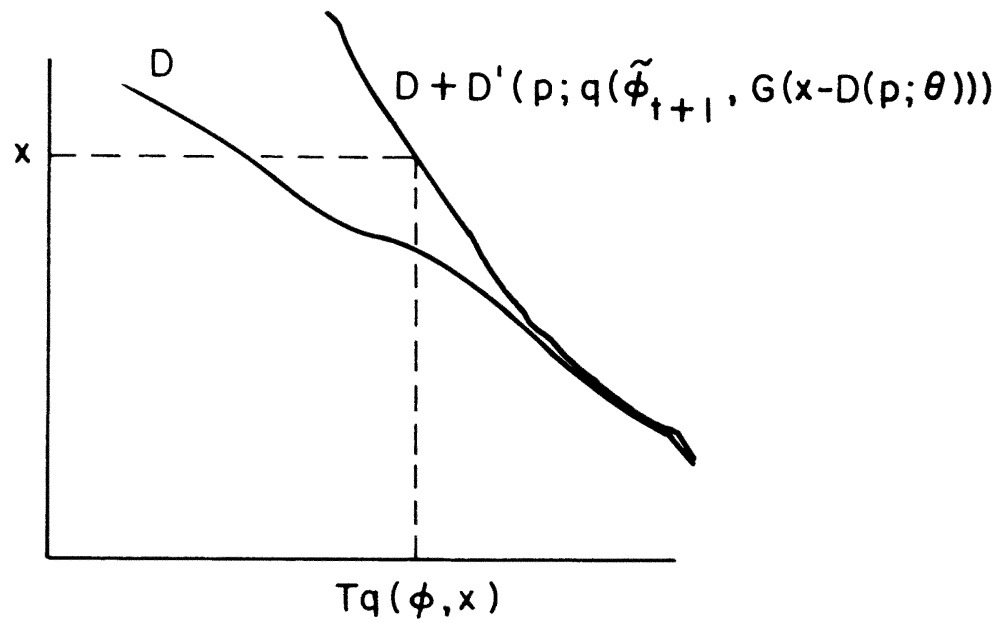

FIG. Al

Estimating $p^{0}-T q\left(\phi, X^{\prime}\right)$ is easy; the fact that $D+D^{\prime}$ is more steeply sloped than is $D$ together with our upper bound on the slope of the inverse demand function $P$ imply that $p^{0}-T q\left(\phi, X^{\prime}\right) \leq \gamma\left(X^{\prime}-X\right)$. As for $T q(\phi, X)-p^{0}$, note that, if $p^{\prime}$ and $p^{\prime \prime}$ are such that $D\left(p^{\prime} ; \theta\right)-D\left(p^{\prime \prime} ; \theta\right) \geq X^{\prime}-X$, then $X-D\left(p^{\prime \prime} ; \theta\right)$ $\geq X^{\prime}-D\left(p^{\prime} ; \theta\right)$, and hence $q\left(\phi_{t+1}, G\left(X-D\left(p^{\prime \prime} ; \theta\right)\right)\right) \leq q\left(\phi_{t+1}, G\left(X^{\prime}-D\left(p^{\prime} ; \theta\right)\right)\right)$ for each $\phi_{t+1}$. Since $D\left(p^{\prime} ; \theta\right)-D\left(p^{\prime \prime} ; \theta\right) \geq X^{\prime}-X>0$ can hold only when $p^{\prime}<$ $p^{\prime \prime}$, this condition implies that

$$
\begin{aligned}
D\left(p^{\prime} ; \theta\right)+ & D^{\prime}\left(p^{\prime} ; F\left(\phi, G\left(X^{\prime}-D\left(p^{\prime} ; \theta\right)\right), q\right)\right)>D\left(p^{\prime \prime} ; \theta\right) \\
& +D^{\prime}\left(p^{\prime \prime} ; F\left(\phi, G\left(X-D\left(p^{\prime \prime} ; \theta\right)\right), q\right)\right) .
\end{aligned}
$$

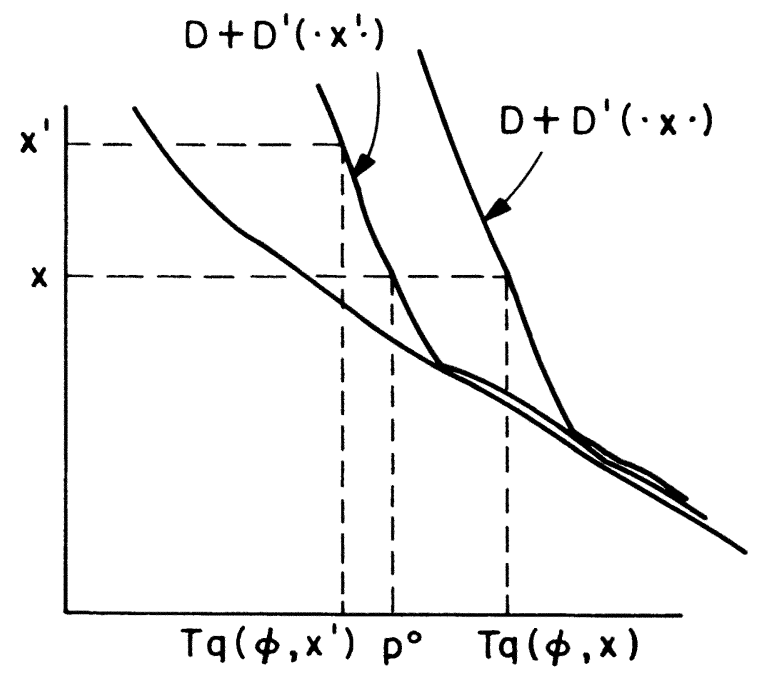

Fig. A2 
Letting $p^{0}$ play the role of $p^{\prime}$ and $T q(\phi, X)$ the role of $p^{\prime \prime}$, the definition of $p^{0}$ implies that $D\left(p^{0} ; \theta\right)-D(T q(\phi, X) ; \theta)<X^{\prime}-X$. Thus by our bound on the slope of the inverse demand function, $p^{0}-T q(\phi, X) \leq \gamma\left(X^{\prime}-X\right)$.

With these two estimates, the proof of the lemma is complete.

The last part of this argument is a bit hard to read through, so let us rephrase it. (The reason we need this last part of the argument will become apparent shortly.) We want to know how much equilibrium prices will change as we move from supply level $X$ to a (higher) level $X^{\prime}$. We take the change in two pieces. First (and this corresponds to the second estimate above) imagine that the "extra" $X^{\prime}-X$ is put into storage for a period-without trying to account for who is doing so. At the equilibrium price for $X$, speculators will react to this by lessening their demand since the extra will depress next period's price. But then equilibrium price this period will fall. The estimate simply says that the fall in equilibrium price cannot be more than the amount that causes consumers to absorb the extra since when that happens total storage will be back to its original level and speculative demand will be restored to its original level (or, owing to the lower current price, more). Second, prices must fall so that someone is really absorbing the extra units. But again the price decline cannot be more than it would take to put these units in the hands of consumers since speculative demand will only rise. Since we have (by assumption) put a uniform upper bound on the elasticity of demand of consumers, we get the estimates given above.

LEMMA A2. Let $q$ and $q^{\prime}$ be two functions from $\Phi \times[X, \bar{X}] \rightarrow[0, \infty)$ that are both continuous and nonincreasing in their second arguments and that satisfy $q \leq q^{\prime} \leq \bar{p}$. Then $T q \leq T q^{\prime}$.

Proof. Fixing $\phi=(\theta, \xi)$ and $X, q \leq q^{\prime}$ implies that, for each $p$,

$$
D^{\prime}(p ; F(\phi, G(X-D(p ; \theta)), q)) \leq D^{\prime}\left(p ; F\left(\phi, G(X-D(p ; \theta)), q^{\prime}\right)\right) .
$$

Thus moving from $q$ to $q^{\prime}$ in figure Al amounts to a shift outward of the $D+$ $D^{\prime}$ schedule and, hence, an increase (weakly) in $T q(\phi, X)$.

Proof of Proposition 1. We can now proceed to prove proposition 1. Define $p^{0}$ $\equiv 0$, and let $p^{1}=T p^{0}, p^{2}=T p^{1}$, and so on. (The interpretation is that $p^{n}$ is the equilibrium price if speculators will disappear in $n$ periods.) Lemma Al ensures that each step of the construction is feasible, that each $p^{n}$ is strictly decreasing and $2 \gamma$-Lipschitzian (hence continuous) in its second argument, and that $p \leq p^{n} \leq \bar{p}$ for each $n$. Lemma A2 ensures that $p^{n+1} \geq p^{n}$. Thus the limit function $p^{*}=\lim _{n \rightarrow \infty} p^{n}$ is well defined, it is nonincreasing and $2 \gamma$ Lipschitzian, and it satisfies $p \leq p^{*} \leq \bar{p}$. (Note that here is where we use the Lipschitzian property: simple continuity of the $p^{n}$ would not necessarily imply continuity of $p^{*}$.)

Because $p^{*}$ and the $p^{n}$ are all equi-Lipschitzian, we can "pass to the limit" in (A1), showing that $T p^{*}=p^{*}$ and (hence) that $p^{*}$ is an equilibrium. Precisely, for every $X$ and $\phi=(\theta, \xi)$, the continuity of $G$ and $D$ implies that $G(X-$ $\left.D\left(p^{n}(\phi, X) ; \theta\right)\right)$ approaches $G\left(X-D\left(p^{*}(\phi, X) ; \theta\right)\right)$. And thus the equicontinuity of $p^{*}$ and the $p^{n}$ implies that, for each $\phi_{t+1}, p^{n}\left(\phi_{t+1}, G\left(X-D\left(p^{n}(\phi, X) ; \theta\right)\right)\right)$ approaches $p^{*}\left(\phi_{t+1}, G\left(X-D\left(p^{*}(\phi, X) ; \theta\right)\right)\right)$. The assumed continuity of the $D^{\prime}$ function then gives the desired result.

Application of lemma Al once more implies that $p^{*}$ (now shown equal to $T p^{*}$ for a nonincreasing $\left.p^{*}\right)$ is strictly decreasing. To show that $X-D\left(p^{*}(\phi\right.$, $X) ; \theta)$ is increasing in $X$, suppose that $X>X^{\prime}$ but $X-D\left(p^{*}(\phi, X) ; \theta\right)<X^{\prime}-$ $D\left(p^{*}\left(\phi, X^{\prime}\right) ; \theta\right)$. Storage is less this period under $X$ than $X^{\prime}$, so next period's prices will be no smaller under $X$. And current price is lower under $X$. Hence 
speculative demand can be no lower under $X$, contradicting the supposition that it is strictly lower.

It remains to show that this equilibrium is unique. The first step is to show that equilibrium prices are bounded above. Since supply is never less than $\underline{X}$, we can apply assumption 6 to get this trivially: Pick $p$ large enough that $D(p ; \bar{\theta})$ $<\underline{X} / 2$ and that $D^{\prime}(p ; \cdot)<\underline{X} / 2$. Clearly, no equilibrium price could ever exceed this $p$.

Next, we argue that, if $\tilde{p}$ is any other equilibrium, then $\tilde{p} \geq p^{*}$. To see this, we must strengthen lemma A2 to read: If $q$ and $q^{\prime}$ are functions such that (i) $q$ is continuous and nonincreasing in its second argument and is less than or equal to $\bar{p}$, (ii) $q^{\prime}$ is such that there is some solution $T q^{\prime}$ of (A2), and (iii) $q \leq q^{\prime}$, then $T q \leq T q^{\prime}$ (for the unique solution $T q$ and any solution $T q^{\prime}$ ). This strengthening is easy: simply review the argument given and/or draw the appropriate picture. With this result, proceed as follows: Since prices are nonnegative, $\bar{p} \geq p^{0}$. Applying the result inductively yields $T \tilde{p}=\tilde{p} \geq T p^{n}$ $=p^{n+1}$ for all $n$, and (hence) $\tilde{p} \geq p^{*}$.

Finally, suppose that we knew that there was some $\left(\phi^{0}, X^{0}\right)$ that achieved the maximum value in $\tilde{p}(\phi, X) / p^{*}(\phi, X)$. Then the distribution of "rates of return" under $\tilde{p}$ starting from $\left(\phi^{0}, X^{0}\right)$ will be no larger (stochastically) than the distribution of rates of return under $p^{*}$ at the same point. Then assumption 7 implies that speculative demand under $\bar{p}$ can be no larger at this point than it is under $p^{*}$. And, since $\tilde{p} \geq p^{*}$, consumption demand can be no higher. Thus to satisfy market clearing, $p\left(\phi^{0}, X^{0}\right)=p^{*}\left(\phi^{0}, X^{0}\right)$ (or else there would be a shortfall in consumption demand). Since $\left(\phi^{0}, X^{0}\right)$ is presumed to maximize the ratio $\tilde{p} / p^{*}$, this implies that $\tilde{p} \equiv p^{*}$.

This argument is not quite complete since it assumes that there is some $\left(\phi^{0}\right.$, $\left.X^{0}\right)$ that attains the maximum in the ratios. As the domain of possible $(\phi, X)$ is compact, if we knew that $\tilde{p}$ was continuous, we would be done. But even if $\tilde{p}$ is not necessarily continuous, the argument goes through with a bit of care: Look along a sequence of $(\phi, X)$ that attains (in the limit) the supremum of $\tilde{p}(\phi, X) / p^{*}(\phi, X)$. Picking a subsequence if necessary, we can assume that $\tilde{p}\left(\phi^{\prime}\right.$, $G(X-D(\tilde{p}(\phi, X) ; \theta)))$ converges along this sequence for every $\phi^{\prime}$. Now apply the argument above to show that, for this limit distribution of next period's prices, there will be a nonvanishing shortfall in demand as long as the supremum of $\tilde{p}(\phi, X) / p^{*}(\phi, X)$ is strictly greater than one. Applying the continuity of $D$ and $D^{\prime}$ near this limit completes the argument.

In our definition of equilibrium, we specifically assume time homogeneity. It is worth noting that time-inhomogeneous equilibria are ruled out by an argument similar to the one just given. The key is that, because of assumption 6 , equilibrium prices must be uniformly bounded. So one would look for a triple $(t, \phi, X)$ that achieves close to the supremum of $\tilde{p}_{t}(\phi, X) / p^{*}(\phi, X)$ and then proceed as above.

Proof of Proposition 2. We have already shown that $p^{*} \leq \bar{p}$. Suppose that for some $\xi$ we had $p^{*}((\bar{\theta}, \xi), \underline{X})<\bar{p}$. Then consumption demand at this price would exceed $\underline{X}$, a contradiction.

\section{References}

$\rightarrow$ Baumol, William J. "Speculation, Profitability, and Stability." Rev. Econ. and Statis. 39 (August 1957): 263-71.

$\rightarrow$ Diamond, Peter A., and Stiglitz, Joseph E. "Increases in Risk and in Risk Aversion." J. Econ. Theory 8 (July 1974): 337-60. 
Farrell, Michael J. "Profitable Speculation.” Economica 33 (May 1966): 18393.

Friedman, Milton. Essays in Positive Economics. Chicago: Univ. Chicago Press, 1953.

Goss, B. A., and Yamey, Basil S. The Economics of Futures Trading: Readings. 2d ed. London: Macmillan, 1978.

$\rightarrow$ Johnson, Harry G. "Destabilizing Speculation: A General Equilibrium Approach.”J.P.E. 84 (February 1976): 101-8.

Kleidon, Allan W. "Bias in Small Sample Tests of Stock Price Rationality." J. Bus. 59 (April 1986): 237-61.

Kohn, Meir. "Competitive Speculation." Econometrica 46 (September 1978): $1061-76$.

$\rightarrow$ Krasker, William S. "The 'Peso Problem' in Testing the Efficiency of Forward Exchange Markets.” J. Monetary Econ. 6 (April 1980): 269-76.

Mill, John Stuart. Principles of Political Economy, with Some of Their Applications to Social Philosophy. London: Longmans, Green, 1921.

Newbery, David M. G., and Stiglitz, Joseph E. "Pareto Inferior Trade." Rev. Econ. Studies 51 (January 1984): 1-12.

$\rightarrow$ Rothschild, Michael, and Stiglitz, Joseph E. "Increasing Risk: 1. A Definition." J. Econ. Theory 2 (September 1970): 225-43.

$\rightarrow$ Samuelson, Paul A. "Stochastic Speculative Price." Proc. Nat. Acad. Sci. 68 (February 1971): 335-37.

Scheinkman, José A., and Schechtman, Jack. "A Simple Competitive Model with Production and Storage." Rev. Econ. Studies 50 (July 1983): 427-41.

$\rightarrow$ Shiller, Robert J. "Do Stock Prices Move Too Much to Be Justified by Subsequent Changes in Dividends?” A.E.R. 71 (June 1981): 421-36. (a)

- "The Use of Volatility Measures in Assessing Market Efficiency." $J$. Finance 36 (May 1981): 291-304. (b)

Smith, Adam. An Inquiry into the Nature and Causes of the Wealth of Nations. 5th ed. 1789. Reprint, edited by Edwin Cannan. New York: Modern Library, 1937.

$\rightarrow$ Telser, Lester G. "A Theory of Speculation Relating Profitability and Stability." Rev. Econ. and Statis. 41 (August 1959): 295-301.

Wright, Brian D., and Williams, Jeffrey C. "The Economic Role of Commodity Storage.” Econ. J. 92 (September 1982): 596-614. 